\title{
CONTRIBUCIÓN A LA IDENTIDAD DEL LIBRO DE NÚMEROS
}

Según el título que el cuarto libro del Pentateuco lleva en griego, su característica principal y distintiva serían las listas numéricas, que en lenguaje moderno podrían llamarse estadísticas. Y, de hecho, el libro las presenta con una cierta frecuencia a partir ya de su capítulo primero. El título griego Arithmoi ha pasado después al latín y a casi todas las lenguas modernas. No a todas: en la tradición de las Biblias alemanas, los libros del Pentateuco son designados por el nombre de su (presunto) autor, Moisés, con el número de orden que les corresponde según su posición en el Pentateuco. Así, Números es el Viertes Moses Buch. El original hebreo, como es sabido, carece de títulos y se conforma con designar los cinco libros por las primeras palabras que se consideran más significativas del original. Así, Números es simplemente $B a$ midbar [Sinai], porque es allí donde wajeddaber: «Habló YHWH a Moisés» ${ }^{1}$.

Si se considera que los «números» no son por ventura la única o la mejor forma para identificar este libro del Pentateuco, se puede preguntar, con igual derecho, si el título que la misma tradición greco-latina atribuye al tercer libro, Levítico, no correspondería más bien al cuarto. Como he notado en mi libro sobre este ${ }^{2}$, los levitas aparecen una sola vez (Lv 25,32-34) en el mencionado libro y de manera más bien marginal. En cambio, basta abrir Números para encontrarse desde el principio y prácticamente hasta el final precisamente con esta categoría de personas ${ }^{3}$. Se podría

\footnotetext{
${ }^{1}$ Es curioso constatar que la tradición ya antigua de identificar los documentos pontificios (las encíclicas, por ejemplo) por las primeras palabras del texto latino sigue el mismo principio.

${ }^{2}$ Guía para una lectura cristiana del Levítico .Buenos Aires, Agape, 2013.

${ }^{3}$ Una primera cuenta concluye con unos cincuenta textos donde se mencionan expresamente los levitas en $\mathrm{Nm}$.
} 
adecuadamente afirmar que «Números» se llamaría mejor «Levítico» que el libro que actualmente (y universalmente, con la excepción más arriba indicada) lleva tal nombre.

En lo que sigue en esta nota me propongo enumerar y brevemente comentar los pasajes que se refieren a los levitas en el libro de los Números, pasajes que, se puede justamente afirmar, contribuyen a su identidad tanto o más que las listas numéricas, no sin reconocer desde ya que, más de un pasaje dedicado a los levitas contiene precisamente una de esas listas.

\section{El censo aparte de los levitas (el primero)}

Nm 1,45-51. El libro comienza con la orden de YHWH a Moisés de hacer el censo de las tribus en vista, por encima del Levítico, de la continuación de la marcha por el desierto, después de la experiencia determinante de la revelación del Sinaí, con la indicación precisa de la fecha en que se da la orden y el lugar en que es comunicada. El texto dice: «En el segundo año después de la salida de Egipto, el primer día del segundo mes, el Señor dijo a Moisés en el desierto del Sinaí, en la carpa del encuentro» ${ }^{4}$. La mención de la «carpa» ${ }^{5}$ o el «tabernáculo» subraya desde ya el carácter sacro y no meramente estadístico del censo que sigue, tribu por tribu $(1,2-45)$, con los asistentes que ayudan a Moisés en esta no grata ni fácil tarea.

La cuenta, el lector atento enseguida lo advierte, no enumera más que once tribus. Para respetar el número clásico de doce, los «hijos de José» son contados como dos: Efraín y Manasés. Y se nos dice al final (vv. 47ss): «Pero la tribu de Leví no fue registrada con las otras tribus, porque el Señor había dicho a Moisés: "No inscribas en el registro a la tribu de Leví ni la incluyas en el censo de los israelitas"». Y aquí comienzan ya las peculiaridades que, a lo largo del libro, distinguirán a esta tribu de las otras.

${ }^{4}$ La versión es la de El Libro del Pueblo de Dios. La Biblia, generalmente utilizada aquí. Otras versiones (La Biblia de Jerusalén, por ejemplo, en sus diferentes traducciones) prefieren seguir literalmente el texto hebreo y comenzar por «YHWH habló a Moisés». No sin razón, en la opinión de quien escribe. Para la crítica histórica actual (y ya antigua), este pasaje pertenecería a la sección histórica del Códice Sacerdotal, $\mathrm{P}$, indicado con la sigla $\mathrm{Pg}$, donde la «g» responde al término alemán Geschichte (historia).

${ }^{5}$ Quien escribe prefiere «Tabernáculo», como he explicado en mi libro citado en la nota 2 . 
En los versos siguientes se da una primera razón de esta omisión de los levitas en el censo: se les encomendará, por orden divina: «El cuidado de la Morada del testimonio, de sus enseres y de todo lo que está relacionado con ella». Del transporte de la misma y de su armado y desarmado cuando la comunidad se desplace o se detenga. Y ellos tendrán además un lugar propio en el campamento, alrededor del Tabernáculo. Todo esto, que será especificado después, para evitar, bajo peligro de muerte, que los demás israelitas y en realidad cualquier extraño (zar) se acerquen demasiado al lugar sacro (vv. 50-53).

Lo notable es que poco después (3,14-39), el mismo Señor ordena a Moisés «inscribir en un registro por familias y por clanes a todos los levitas varones que tengan más de un mes» (v. 15). Exactamente la misma fórmula que se había usado antes para el censo de los demás israelitas, del cual los levitas habían sido expresamente excluidos, como se ha visto, excepto el límite de edad de los censados: aquí son los de más de un mes (es decir, prácticamente los recién nacidos, varones por cierto); allí eran (cf. 1,18) «los que tenían más de veinte años». La diferencia en el límite de edad se explica porque el censo general tiene en vista «los que son aptos para la guerra» (cf. 1,3). La misión de la tribu de Leví es otra y se quiere sin duda subrayar que esta otra misión les pertenece por derecho de nacimiento.

Queda sin embargo por explicar el cambio tan radical en pocas líneas de la omisión por orden divina del censo a la orden contraria de hacerlo. La solución fácil y con frecuencia aplicada en el análisis histórico-crítico de estos textos es que se trata simplemente de una tradición diversa, registrada junto a la anterior. Pero esto presupone que el o los redactores yuxtaponían casi materialmente textos sin preocuparse de la coherencia interna del relato. Presupuesto que parece siempre menos aceptable: el o los redactores, se supone, procedían con mayor inteligencia y con precisos puntos de vista. La cuestión que se propone al lector contemporáneo es tratar de discernir, en lo posible, cuáles eran o podrían ser tales puntos de vista.

La probable explicación es que aquí se considera la tribu de Leví una casta consagrada al servicio del Señor de manera exclusiva, libre por consiguiente del servicio militar y lo que va con él, como las restantes tribus. Su identificación numérica se hace aparte, en función de las necesidades del Tabernáculo, y como esta dedicación a lo sacro es inherente a su carácter de tribu, la numeración se hace prácticamente a partir del nacimiento.

De todos modos, aun en la tribu de Leví, según la concepción aquí representada (y en los pasajes correspondientes de Ex y de Lv), hay distinciones internas imposibles de superar.

A esto mira, por un parte, la breve genealogía puesta no sin motivo al principio del cap. 3, donde ya Moisés y Aarón (en 3,1 en orden inverso), 
pero sobre todo este último y sus hijos sobrevivientes al episodio narrado en Lv 10,1-2 y aquí expresamente referido, son calificados de «sacerdotes ungidos» «cuyas manos fueron consagradas para ejercer el sacerdocio» $(3,3)^{6}$. Los levitas, en cambio, como se dice enseguida, ajenos a toda consagración de este tipo (tendrán, sin embargo, una propia, como se verá más tarde), «están a disposición de Aarón para servirlo» (v. 6) y al servicio de «la comunidad de Israel... encargándose del servicio de la Morada» o Santuario y del Tabernáculo (v. 7).

Todo esto significa que los levitas, si bien miembros de una tribu con carácter «sacral», son esencialmente distintos, en la concepción aquí representada, de los sacerdotes, al rango de los cuales no pueden pretender (como se verá en el cap. 16 con el dramático relato de Coré, él mismo levita): su existencia y su función requieren ser de algún modo justificados. Y este es, si no me equivoco, uno de los temas característicos del libro de los Números, que así comienza por hacer recuento numérico, en realidad parte fundamental de su identificación y su división en clanes y familias, como se lee en la continuación del cap. 3. Es preciso saber, para determinar sus funciones, quiénes son en Israel exactamente levitas (aunque no aarónidas) y cuántos son en cada familia y cada clan. Esto en la perspectiva del libro de $\mathrm{Nm}$, que proyecta sin duda una situación muy posterior (según trataré de hacer ver después) en el período normativo del Sinaí y del desierto.

\section{La genealogía de los levitas ${ }^{7}$}

Se vuelve entonces a la genealogía, ahora desde este especial punto de vista. Comencemos, sin embargo, por notar que, según la genealogía que se lee en $\mathrm{Nm} 26,59^{8}$, Moisés y Aarón proceden del segundo (en cuanto

${ }^{6}$ Versión de la Biblia de Jerusalén. El Libro del Pueblo de Dios parafrasea: «Recibieron... la investidura para ejercer el sacerdocio». También la versión de la BJ tiene un inconfundible eco moderno. El original dice que las «manos» de los sacerdotes fueron «colmadas», con el verbo en activo: «alguien» (de hecho Moisés según Lv 8,27) puso en «las manos» de Aarón y de sus hijos los dones sacrificiales. Este «colmar las manos» es parte de la ceremonia de consagración sacerdotal y acaba por designarla sintéticamente aquí y en otros textos.

${ }^{7}$ Las tres ramas principales nunca cambian, pero hay diferencias con los clanes de segundo nivel y en el orden de los mismos: cf. $1 \mathrm{Cr}$ 5,27-6,15.

${ }^{8}$ En el segundo censo de $\mathrm{Nm}$. La misma que se lee en Ex 6,17-20 (cf. también $1 \mathrm{Cr} 5,27-28)$. Y que sin duda procede de la misma fuente. Y esta conexión familiar no deja de tener su importancia en el relato. 
enumerados aquí) de los clanes o familias de hijos de Levíi : los hijos de Quehat. Los clanes son, en efecto, tres, Gersón, Quehat y Merarí. A primera vista, los quehatitas parecen no solo los más numerosos (lo cual es ya significativo): 8.300 contra 7.500 de los gersonitas y 6.200 de los meraritas, sino además acampan al sur de la Morada: el sur o la derecha es el lado favorable en la tradición bíblica, y sobre todo tienen a su cargo, en su tarea de ocuparse de los objetos sacros, los que son entre todos los más sagrados: «El arca, la mesa [de los panes de proposición], el candelabro y los [dos] altares», además de «los utensilios sacros que se usaban en el culto» $(3,27-$ $31)$. Esta propia responsabilidad será objeto de rigurosa precisión más adelante. En 4,4 se dice expresamente. «Los quehatitas serán los responsables en la Carpa del Encuentro de los objetos más santos». No en vano a la familia de Quehat pertenecían, es verdad, en su propio nivel superior, Moisés, Aarón y, por consiguiente, todos los aarónidas. Los levitas de las otras dos ramas se ocupan del embalaje y el transporte de otras partes del Santuario menos importantes.

De esta disposición genealógica de los levitas depende también, siempre según el esquema del cap. 3, la posición de los mismos respecto del Santuario en la marcha por el desierto, concebida y presentada como una especie de procesión litúrgica que nada pudiera alterar. Así (v. 23), los guersonitas «acampaban detrás del Santuario hacia el oeste» (v. 29); los quehatitas «acampaban en el lado sur [el lado preferible] del Santuario» (v. 35b); los meraritas, «al lado norte». Y al este, frente a la Morada o al Santuario, «acampaban Moisés, Aarón y sus hijos» (v. 38a), en directa relación con él. Y la conclusión es, según se podía esperar (v. 38c): «Cualquier extraño [zar] que se acercara debía ser castigado con la muerte».

\section{El segundo censo de los levitas ${ }^{10}$}

Si el cap. 3 contiene ya, como se ha visto, un primer censo de los levitas, con su distribución en clanes o familias, con una primera descripción de las tareas que corresponden a cada uno de los clanes en la tarea del transporte del Santuario o Morada y las partes que la componen, donde ya predominan los quehatitas, a pesar de figurar en segundo lugar según el riguroso orden genealógico, el cap. 4 ordena a Moisés un nuevo censo de los mismos levitas. Excluidos del primer censo general, ahora gozan de dos.

\footnotetext{
9 Aarón es calificado de «levita» en Ex 4,14: «Aarón, tu hermano el levita».

${ }^{10}$ Habrá todavía un tercero: 26,57-62, que será examinado en su momento.
} 
La razón de este segundo censo, donde los quehatitas ocupan el primer lugar, pero sobre todo son los aarónidas los que presiden la tarea del embalaje y preparación para el transporte de los objetos más sacros, tiende claramente a acentuar la insalvable diferencia entre estos, también quehatitas, pero dotados de consagración sacerdotal, y el resto de sus hermanos del mismo clan simples levitas. Por consiguiente, son los aarónidas que, con instrucciones de preciso detalle, preparan esos objetos más sacros para que luego los (simples) quehatitas se hagan cargo de su transporte en los desplazamientos por el desierto. Inútil entrar en los pormenores precisos de la preparación en cuestión, pero no se puede dejar de notar que, al término de la larga lista de estas instrucciones (4,2-14), nos encontramos con esta afirmación inesperada, dirigida a Moisés y Aarón (y no solamente a Moisés): «No permitas que el grupo de los quehatitas sea eliminado de los levitas» (4,17-18). Y si se pregunta por qué lo sería, la respuesta es: porque, siendo responsables del transporte de los objetos más santos, según se ha visto más arriba, podrían haberlos «visto» (v. 20) o «entrado a verlos» (se entiende en el Tabernáculo). Ahora bien, como se ha dicho más arriba $(3,10 b)$, «... si se acerca un extraño [al Tabernáculo] será castigado con la muerte» (el original dice simplemente: «Será [o caerá] muerto»). Semejante total exclusión, incluso de «entrar a ver por un instante los objetos santísimos» (qodesh qodashim: el superlativo), afecta también a los quehatitas. Los verían si tuvieran que ocuparse de prepararlos para el traslado. Pero de esto se ocupan los aarónidas. Los quehatitas nunca los habrán «tocado» $(4,15)$ : «Y al levantarse el campamento, una vez que Aarón y sus hijos hayan terminado de cubrir los objetos sagrados y sus accesorios, vendrán los hijos de Quehat para transportarlos, pero no tocarán los objetos sagrados, porque morirían». Ni verlos ni mucho menos tocarlos. Solamente cargar con ellos para el traslado. Y lo mismo, con mayor razón, vale de los otros dos clanes, al frente de los cuales está uno de los dos hijos sobrevivientes ${ }^{11}$ de Aarón: Itamar. Al otro, Eleazar, le toca, en cambio, ocuparse de los elementos que sirven más directamente al servicio del culto (v. 16), y además «ejercerá la supervisión sobre toda la Morada, con todos los objetos sagrados y todos los utensilios que hay en ella». Nueva acentuación de la diferencia entre las dos categorías.

Este segundo censo parte de otro principio respecto del primero. Se trata de registrar la cantidad numérica de los levitas de los tres clanes que son capaces del esfuerzo (nada leve) de transportar por el desierto sobre sus

${ }^{11}$ La triste suerte de los otros dos en Lv. 10,1-3, ya más arriba aludida: se arrogaron la presentación por su cuenta del fuego y del incienso. 
hombros todos los objetos atinentes al culto. El cálculo se hace entonces no a partir del mes, es decir, prácticamente del nacimiento, sino a partir de la plena adultez, y se incluyen en el cálculo los levitas en la flor de la edad; entre los treinta y los cincuenta años: así 4,1, al ordenar el censo y al final del pasaje (v. 34 para los quehatitas; v. 39 para los gersonitas; v. 42 para los meraritas), cuando se refiere, como es habitual en estos textos que contienen órdenes divinas, a la fiel ejecución de las mismas. El preciso resultado numérico es naturalmente mucho menor que el anterior, pero esta vez la preponderancia va a los meraritas: 3.200 contra 2.750 quehatitas y 2.630 gersonitas, quizá porque el peso a ellos confiado es mayor; les tocan, en efecto, los elementos de la construcción de lo que rodea la Morada, travesaños, columnas, bases, etc.

\section{Justificación de la existencia de los levitas a partir del destino de los primogénitos}

A esta altura tenemos ya una neta distinción, imposible de ser más acentuada, entre aarónidas (es decir, sacerdotes consagrados) y meros levitas. A estos les toca el servicio de los primeros, y uno diría, como second best, de alguna manera el cuidado de los objetos sacros $(3,25.31 .37)$ sin mirarlos ni tocarlos, y sobre todo transportarlos, como acabamos de ver. Resta por ver cómo resultaba posible combinar la primera tarea con las severas exigencias de la segunda para los quehatitas. Y ello bajo amenaza de muerte.

Pero esto no es todo. Otra novedad de estos primeros pasajes de Nm, siempre en relación con la identidad propia de los levitas, es que sustituyen a los primogénitos. Los primogénitos, como se ha legislado desde Ex, pertenecen a YHWH, hombres y animales, y requieren por consiguiente consagración y rescate (13,11-16). Ahora (Nm 3,11-12) se legisla que los levitas toman el lugar de los primogénitos. La fórmula merece ser reproducida literalmente. «Entre todos los israelitas, en lugar de los primogénitos... yo elijo [dice YHWH a Moisés] a los descendientes de Leví. Los levitas me pertenecen, porque todo primogénito me pertenece», con la necesaria referencia al Éxodo: «Cuando exterminé a todos los primogénitos de Egipto, consagré a mí todos los primogénitos de Israel, hombres y animales, a fin de que fueran míos» (v. 13). Y se ratifica esta nueva disposición con la afirmación solemne: «Yo soy el Señor». Hasta aquí, el lector no advierte ninguna distinción dentro de la tribu de Leví, aunque ya el lenguaje mismo orienta la norma solamente a los levitas como tales, distinguidos de los 
sacerdotes consagrados, los aarónidas. El texto siguiente, que completa la descripción del censo de los levitas y sus clanes, en 3,40-51, suprime toda posible duda. Los sustitutos de los primogénitos son los miembros de los tres clanes de los levitas no sacerdotes. Se hace a propósito de esto un censo especial de los primogénitos varones de todos los israelitas de un mes para arriba, el mismo límite inferior de los levitas. El número, como era de esperar, resulta prácticamente idéntico al de los levitas enumerados conforme al mismo principio: 22.000 contra 22.273. El exceso, según el mismo texto, debe ser rescatado a cinco siclos por cabeza, suma que debe ser entregada, se nos dice expresamente, «a Aarón y a sus hijos», conforme a la disposición divina: 1.365 siclos (v. 50). Y además, como según el Éxodo (u.s.) también los primogénitos de los animales (se entiende, los domésticos) son también propiedad divina, el texto presente dispone que el ganado de los levitas ${ }^{12}$ sirva igualmente de sustituto por los primogénitos de los ganados de los israelitas.

Este curioso texto se presta a varios comentarios. El primero es sin duda que entra en la misma categoría de los otros ya examinados: presupuesta la insalvable distinción entre aarónidas y simples levitas, confiere a estos por lo menos la dignidad de sustituir a los primogénitos, estricta propiedad divina, según Ex. Es, a su modo, otro ejemplo del second best a que los simples levitas -se diría- son invitados a resignarse. Un second best de cualquier modo de nivel superior al mero cuidado de los objetos sacros y a la tarea más o menos servil de transportarlos en los desplazamientos. Los simples levitas pertenecen al Señor como los primogénitos. De alguna manera, esta disposición refleja aquella otra conocida que aparece más tarde, en Dt 18,2: aquí para todos los «sacerdotes levitas» de «esta tribu: no poseerán una herencia en medio de sus hermanos: su herencia es el Señor, como él mismo se lo ha declarado» (cf. ya 10,9). Aquí, en esta norma de Nm, son los levitas los que constituyen, en lugar de los primogénitos, «la herencia del Señor». Y más tarde en este mismo libro, en el contexto del segundo censo de todos los israelitas, en vista de la entrada en Canaán, se nos dice también (26,62): «Ellos [los levitas] no figuraron en el censo de los demás israelitas, porque no se les había asignado una propiedad hereditaria entre los israelitas». Pero no se habla de que «su herencia es el Señor». Están además los ganados, que de suyo suponen una propiedad agrícola. Sobre esto volveremos cuando haya que examinar la cuestión (cap. 35) de las ciudades levíticas con sus territorios.

12 Se verá más tarde que, a pesar de la constante afirmación de que los levitas no poseen más propiedad (si es lícito decir) que Dios mismo, poseen sin embargo también propiedades terrenas (cf. cap. 35). 


\section{Hipótesis sobre el posible origen de la distinción entre sacerdotes y levitas}

A esta altura de las cosas, si la distinción prácticamente absoluta entre sacerdocio consagrado y simples levitas es ya un hecho, se experimenta todavía la necesidad de justificarla, con el doble recurso a las disposiciones del desierto, siempre normativas, y a la afirmación de su carácter de sustitutos de los primogénitos como propiedad divina. Cómo se llega a esta distinción no es el caso de examinar ahora. Cuestión histórica complicada donde las haya, y objeto de debate entre los especialistas. Limitémonos por el momento a decir, primero, que los miembros de la tribu de Leví tienen todos ellos, desde antiguo, el carácter especial de «consagrados» al servicio del Señor, como se ve, por ejemplo, en el episodio narrado en el libro de los Jueces $(17,7-13)^{13}$, donde se llama expresamente al levita «sacerdote» (kohen): vv. 10.11.13 ${ }^{14}$. El problema es cómo y por qué se llegó a la distinción ratificada en estos textos de $\mathrm{Nm}$, aunque ignorada todavía en las disposiciones sacrificiales de Lv y en Dt, que no conoce más que «sacerdotes levitas» (cf. 10,8-9; 18,1ss). Es aquí donde se dividen las explicaciones ${ }^{15}$.

${ }^{13}$ Aquí, curiosamente (cf. v. 12), es el dueño de casa (o, si se quiere, el «empleador») quien «colma las manos» de su «sacerdote». Es decir, no lo «consagra»: no se ve con qué autoridad lo haría, sino simplemente que lo acepta como tal y provee a su sustento. La expresión «colmar las manos» es así usada también otras veces en un sentido que se puede llamar «laico».

${ }^{14}$ Este y los capítulos siguientes en Jue $(18,3-15 ; 19,1 ; 20,4)$ son las únicas instancias del singular lewi como sustantivo común antes del Pentateuco, aparte de Ex 4,14 citado en nota anterior. Y el plural apenas conoce dos o tres instancias que se pueden considerar antiguas (una podría ser $1 \mathrm{Sam}$ 6,15). Esto es ya llamativo si se lo compara con el abundantísimo uso del plural solamente en $\mathrm{Nm}$. Se puede afirmar con verdad que el plural lewiyim es uno de los términos característicos de este último libro: unas cincuenta instancias. Cabe notar que, en Ex 32,26.28 lel episodio del becerro de oro), los que ejecutan a los culpables son llamados (bne Lewil en el original hebreo, pero no «levitas» en plural, a pesar de la versión de $E l$ Libro del Pueblo de Dios (que usa el plural en la segunda instancia; v. 28, no en la primera, v. 26).

${ }^{15}$ Sin entrar para nada en esta discusión, no se puede dejar de registrar que el único texto claro que establece una distinción neta entre «levitas» y «sacerdotes levitas», y excluye a los primeros del servicio sacrificial directo: «Presentar la grasa y la sangre», «entrar en ni santuario» y acercarse a la «mesa mía [de YHWH]», es el texto de Ez 44,9-16. Los «levitas» aquí son castigados porque «me abandonaron cuando Israel se descarriaba lejos de mí para seguir a sus ídolos, cargarán con su culpa» (v. 10). Se limitarán en adelante a cuidar las puertas del Templo, a inmolar las víctimas, «el holocausto y el sacrificio para el pueblo», y «estarán ante el 
Personalmente tiendo a pensar que la distinción tiene que ver con la considerable distancia que objetivamente tendía a separar cada vez más a los «sacerdotes levitas» que ministraban en el santuario central de Jerusalén y los que ministraban en los demás santuarios (como los sacerdotes de Nob en 1 Sam 21 o los de Anatot, a los que pertenecía por ejemplo Jeremías, cf. Jr 1,1), incluso no necesariamente del todo idolátricos o sincréticos, y el sacerdocio de la capital con su Templo, incluso antes, pero sobre todo después de la centralización deuteronómica, como se advierte ya en Dt 18,6ss. La distinción, ya bien marcada idealmente por Ezequiel, no podía no acentuarse con el tiempo a medida que Jerusalén y su Templo, sobre todo después del exilio, aparecían como el único lugar legítimo de culto yahvista ${ }^{16}$. Sea de esto lo que fuere, es claro que semejante discriminación, con las consecuencias necesarias que conocemos, no se pudo hacer sin conflicto ni resistencia. Y es de esto de lo que dan indirectamente testimonio los textos recién examinados en $\mathrm{Nm}$, y mucho más directamente otros que examinaremos después: la rebelión de Coré (cap. 16) en primer término.

pueblo para servirlo», «no se aproximarán a mí para ejercer la función sacerdotal» (vv. 11.13). Acerca de este texto, se nota, primero, que es una descripción ideal del futuro, como toda la torá de Ezequiel. Pero se nota sobre todo que alguna distinción entre simples «levitas» y «sacerdotes levitas» existe ya: los unos se hicieron culpables de favorecer la idolatría o el sincretismo, los otros, los descendientes de Sadoc (v. 15), por lo visto se mantuvieron fieles. Los «levitas» serían los que ministraban en los lugares de culto más o menos idolátricos o sincréticos, sacerdotes como los otros, pero considerados infieles. Los textos de $\mathrm{Nm}$ recién examinados parecen demostrar que esta normativa de Ezequiel, si se la pretendió aplicar, no fue aceptada de buen grado y algo hubo que elaborar para satisfacer a los simples «levitas». Por lo demás, no sin dificultad, como se ve por el episodio de Coré. Las precisas funciones de los levitas en el Segundo Templo serán luego especificadas sobre todo en los libros de las Crónicas. Cf. infra, nota 36.

${ }^{16}$ El pasaje de 2 Re sobre la reforma de Josías parece ir precisamente en este sentido. Dice precisamente 23,8-9: «Hizo venir a todos los sacerdotes [kohanim] de las ciudades de Judá [Nob y Anatot son "ciudades de Judá"] y profanó los lugares altos donde... quemaban incienso desde Gueba hasta Beersheba. Pero los sacerdotes de los lugares altos no podían subir al altar del Señor en Jerusalén, aunque comían los panes ácimos en medio de sus hermanos». En cambio (vv. 19-20), a los sacerdotes [kohanim] de los lugares altos que había allí («en las ciudades de Samaría») los «inmoló sobre los altares... y quemó sobre ellos huesos humanos». El texto paralelo de $2 \mathrm{Cr} 23,8-9 ; 35,5.9 .14$; y ya antes, 34,9, «los levitas guardianes del umbral», distingue claramente (y en el sentido de Ezequiel) a los sacerdotes (kohanim) de los levitas (lewiyim). 


\section{La consagración/dedicación oficial de los levitas}

YHWH ordena a Moisés con precisas instrucciones que los levitas sean objeto de una ceremonia de especial consagración a él y a Aarón y sus hijos. De alguna manera, esto ratifica su especial estatuto ya descrito en los capítulos anteriores. Las instrucciones y su estricto cumplimento ocupan todo el cap. 8 de Nm. Después del cap. 7, que enumera las ofrendas de cada tribu en vista de la consagración del Santuario, del altar y los demás objetos sacros, que hace posible el encuentro en él de Moisés con el Señor (vv. 8-9) y el paréntesis sobre las lámparas que acompañan el candelabro $(8,1$ 4), se nos describe el rito de consagración de los servidores de la Morada: los levitas. Es claro el paralelo con el cap. 40 de Ex: erección y consagración de la Morada o el Santuario, la presencia del Señor en él y el cap. 8 de Lv con la consagración sacerdotal de Aarón y de sus hijos. La inserción ahora de los levitas en esta sucesión de textos paralela a la anterior tiende de nuevo a realzar su importancia y su papel, aun en el nivel inferior que es el suyo.

La ceremonia procede por varios pasos. Primero hay que purificar a los candidatos, lo cual se hace por la aspersión con el agua de la purificación, la completa supresión de todo el vello del cuerpo y el lavado de la ropa. Luego se disponen las víctimas para los sacrificios: dos novillos, el primero al menos con la correspondiente oblación que lo acompaña, especificada como siempre, y el segundo «por el pecado». La ceremonia presenta entonces también un carácter expiatorio, según se dice expresamente más abajo (v. 12). Lo que sigue subraya la solemnidad de la misma y su relación con la comunidad entera, convocada por Moisés. Esta debe imponer las manos sobre los levitas puestos en presencia del Señor (o sea, sin duda, ante el Tabernáculo) para hacerlos suyos de alguna manera. Todavía más notable, interviene a continuación Aarón, quien, como en los ritos sacrificiales, hace con los levitas el «gesto litúrgico de presentación ante el Señor» (la tenufah), que los ofrece a él, gesto que se menciona otra vez (v. 13), sin duda para acentuar su importancia. Una vez así «destinados al servicio del Señor» y separados del resto de la comunidad, ellos a su vez imponen las manos sobre los animales destinados al sacrificio, que ahora pueden ser inmolados. Uno como holocausto, el otro en rito de expiación ( $k p r)$ por los mismos levitas. Así quedan «separados» del resto de la comunidad, en cuanto «donados» (netunim, 2x en v. 16) a YHWH y él los «da» (la misma expresión) a Aarón y a sus hijos, y entonces están en condiciones de ejercer su servicio en el Tabernáculo. Esta consagración es a su vez puesta en relación directa con la consagración de los primogénitos a YHWH, cuyo 
lugar ocupan (v. 16) con la misma referencia a la supresión de los primogénitos de los egipcios, como ya se nos ha enseñado en 3,11-13. Una vez más, entonces, la dignidad de una pertenencia a YHWH en lugar de los primogénitos y la sumisión al servicio de los sacerdotes, a Aarón y sus hijos. Es la grandeza y la pequeñez de los levitas, en la concepción tan especial de este libro. Es claro, de cualquier modo, que esta presentación de un rito de consagración no consideraba para nada a los levitas sacerdotes: la haría del todo superflua. A menos que se considere que, si en un tiempo se les había considerado sacerdotes, como los aarónidas (o los sadócidas), por alguna razón habrían sido degradados. Pero esto no parece constar en ninguna parte, a menos que se interprete así Ez 44,9-16, que puede (y quizá debe) ser leído de otro modo, como he notado más arriba.

Los últimos versos del capítulo reiteran los límites de edad del servicio, que ya no se ciñe solamente al armado y desarmado de los objetos sacros y a su transporte, pero mantiene casi los mismos límites: de veinticinco a cincuenta años, con la afirmación anexa de que, después de esa edad «de retiro», pueden los levitas «ancianos» ayudar a sus hermanos en su servicio propio. Antes $(4,47)$, el límite superior eran los treinta. Se nota también que aquí este servicio es expresado con los términos característicos del servicio militar: lisbo saba'... jashub mi saba' (vv. 24.25), reservado antes al servicio propio de las otras tribus (cf. 1,3ss) ${ }^{17}$.

\section{La rebelión de Coré, Datán y Abirán}

Los caps. 16-18, pero sobre todo 16-17, vuelven sobre el problema de la relación entre levitas y sacerdotes, y ante todo sobre la distinción entre unos y otros. A esta cuestión, la redacción actual de 16-17 ha asociado otra, entretejiendo ambas (no quizá sin motivos objetivos): la rebelión contra la autoridad de Moisés y su derecho a conducir de manera exclusiva a la comunidad por el desierto. La primera cuestión ha sido vinculada con el nombre de un levita quehatita, Coré; la otra, con los rubenitas Datán y Abirán, ambos -parecería- con sus respectivos grupos.

La primera cuestión se expresa en los términos que se podían esperar, conforme a la enseñanza de los textos anteriores: «Escúchenme, hijos

${ }^{17}$ Queda pendiente en todo esto el problema del sustento material cotidiano de los levitas. Tampoco los sacerdotes excluidos del servicio del altar en 2 Re 8-9 pueden solo vivir de «panes ácimos». Sobre esto se volverá más adelante, en el cap. 18, pero también cuando examinemos la cuestión de las ciudades levíticas. 
de Leví: ¿no les basta que el Señor los haya separado de toda la comunidad de Israel y los haya acercado a él para prestar servicios en la Morada del Señor y para estar como ministros al frente de la comunidad? El Señor te promovió a ti [la segunda persona mira aquí directamente a Coré] y a todos tus hermanos, los descendientes de Leví, ¿y todavía reclaman el sacerdocio?». El objeto de la rebelión no puede haber sido puesto en términos más explícitos. Esto no obstante, quedaría por explicar la frase siguiente: «Porque, ¿quién es Aarón para que ustedes protesten contra él?». Significaría en el contexto no una disminución de la preeminencia de Aarón, sino que la rebelión es en realidad contra el mismo YHWH, que ha elegido a Aarón, como los textos anteriores afirman. Y, de hecho, la solución del desafío, la primera por lo menos y la más directa, es contraponer ante el mismo Señor aparecido en su gloria (v. 19) en su Tabernáculo la autenticidad del ejercicio de la función sacerdotal de Coré y sus secuaces y la del mismo Aarón, con el recurso de los incensarios listos para arder con incienso, pero sin el fuego dentro (vv. 14-21). El resultado de la prueba no nos es narrado de manera directa, pero sí su consecuencia. Coré y sus secuaces con sus familias y sus bienes son tragados por la tierra, que se abre para devorarlos (vv. 30-33). La frase final no deja lugar a dudas sobre el final de los que, a pesar de todo, habían ofrecido incienso (v. 33). Y lo mismo se desprende del principio del cap. 17, cuando, por orden de YHWH, Eleazar («hijo de Aarón», pero no el mismo Aarón) debe recoger los incensarios que han quedado desparramados con su contenido (carbones y cenizas) por el suelo, porque de alguna manera están «santificados» (vv. 2-4) y no pueden ni ser descartados ni destinados a cualquier otro uso. Sean trasformados en láminas de metal para revestir «el altar» (se supone siempre el del incienso) y servir así de «memorial» (zikkaron) para los israelitas, y nadie, «ningún profano» ('ish zar) que no sea de la progenie de Aarón se atreva a ofrecer incienso ante YHWH, para que no le suceda lo que le sucedió a Coré y su grupo (17,1-5).

Es fácil advertir ya en esta historia los elementos que, a primera vista, parecen entre sí contradictorios. Se pueden registrar dos o tres. Primero: ¿estaba Coré acompañado de otros secuaces (obviamente también levitas)? Desde el principio del cap. 16 se mencionan 250 rebeldes $(16,2)$, calificados, sin embargo, no de levitas, sino de «príncipes», «personas de renombre en la comunidad» (versión propia). ¿Habrían osado estos personajes presentarse con los incensarios ante el altar? ¿O bien pertenecen a la rebelión por así decir «civil» de Datán y Abirán? De cualquier modo, el doble relato del fin de Coré y de los incensarios desparramados y recogidos recién referido parece suponer que Coré, en la redacción actual, es 
presentado como no estando solo. Y si la dramática descripción de la tierra abierta y el descenso de los culpables vivos al she'ol, presentada por Moisés como prueba o confirmación de su indiscutible autoridad divina (vv. 28-34), comienza por nombrar a los rebeldes «civiles» (v. 25), también, como ya hemos notado, incluye en este espectacular castigo (descrito con el verbo que significa «crear») también «a la gente de Coré con todos sus bienes» (vv. 32-33).

Y lo mismo presupone el episodio de los incensarios recogidos (17,1-5). La única explicación posible del texto como ahora lo leemos, aparte de la contaminación de un relato con el otro ya mencionada, es que Coré tampoco estuviera solo, sino acompañado de otros levitas, aunque estos nunca son mencionados. Si es así, las dos rebeliones fueron de alguna manera «comunes» hasta cierto punto o «colectivas». En cambio, en el conmovedor acto de intercesión de Moisés y Aarón (16,21-22): después de insistir en que los culpables sean dejados solos para que los demás israelitas no sean víctima del mismo castigo, dicen al Señor postrados en tierra: «Dios de los dioses [versión literal mía; el original tiene una fórmula inusitada: El Elohim (este segundo título en combinación con la palabra siguiente, lo que en hebreo se llama "estado constructo") de los espíritus de toda carne ${ }^{18}$, ¿te indignarás con toda la comunidad si es un solo hombre que ha pecado?». Esto no puede sino referirse a un solo responsable de la rebelión: Coré; o bien porque en efecto al principio era el único rebelde entre sus hermanos levitas, y a él luego se asociaron otros, o bien la fórmula de intercesión como ahora es presupone ya la contaminación de los dos relatos. Sea como fuere, es penoso comprobar que, a diferencia de otras intercesiones de Moisés (con o sin Aarón), esta no fue escuchada por el Señor.

Nuestras dificultades no concluyen aquí. Aun dejando de lado la rebelión «civil» de Datán y Abirán, si no en cuanto imbricada actualmente con la de Coré (con o sin secuaces), comprobamos que la ira del Señor no se ha aplacado todavía y el mismo Señor, aparecido en la nube que oculta y a la vez manifiesta su gloria, amenaza con otro castigo, general esta vez, sin duda en relación con las dos rebeliones. Moisés es aconsejado que se separe de la comunidad para no ser devorado «en un instante», sin duda por la tierra de nuevo abierta. Aquí aparece de nuevo el incensario, esta vez manejado por Aarón, luego de la intensa intercesión da ambos rostro en

${ }^{18}$ La misma expresión, pero con YHWH en lugar de El Elohim, en la oración de Moisés en 27,16, cuando se le anuncia su muerte para que YHWH no deje a Israel como «ovejas sin pastor». 
tierra (17,1-15, cita en $10 \mathrm{~b})$, para que cese la plaga que entretanto ya ha comenzado y causado catorce mil víctimas. Pero la acción expiatoria (verbo $k p r$, como de ordinario) de Aarón con su incensario «en medio de los muertos y los vivos» (v. 13) la detiene.

Este triste relato nos interesa directamente porque mira sin duda a ensalzar a Aarón, esta vez delante de toda la comunidad y no solamente de los levitas, que objetaban con Coré (y sus secuaces, si los tenía), si no ante la comunidad entera. Es el episodio de la vara florecida $(17,16 \mathrm{ss})$, la única entre las varas de los representantes de toda la comunidad, los «príncipes» (la expresión es la misma en el original que hemos encontrado en mi propia versión al principio de toda esta historia de rebeliones en 16,2). También la autoridad de Aarón, y no solamente la de Moisés, ha sido puesta en cuestión, y no solo por los levitas, sino aparentemente por todos ${ }^{19}$.

$\mathrm{Nm}$ 17,6 dice claramente: «Al día siguiente [del episodio de los incensarios], toda la comunidad de los israelitas protestó contra Moisés y Aarón diciendo: "Ustedes han provocado una mortandad en el pueblo del Señor"». Mortandad suspendida por la intercesión de Aarón y su acto de expiación con el rito del incienso recién referido (vv. 11-15). A pesar de lo cual parece todavía necesaria una manifestación prodigiosa de la preeminencia de Aarón, no solo entonces como sacerdote supremo, sino también como jefe de la comunidad junto con Moisés. Las varas son designadas con la misma palabra hebrea que significa «tribu» (mathot), lo cual parece implicar que son de alguna manera los «bastones»o «cetros» signo de la autoridad de los «príncipes» de cada una de ellas. Más entonces que simples

${ }^{19}$ Es verdad que Aarón, no obstante su papel preeminente a lo largo del Éxodo, el Levítico y hasta ahora en Números, ha tenido una actitud por lo menos ambigua en el episodio del becerro de oro (Ex 32,1 ss), y aquí los «hijos de Leví», a los cuales en principio pertenece también Aarón, son los que reaccionan de parte de Moisés y ejecutan el castigo de los israelitas idólatras (o al menos sincretistas) y reciben por eso en premio «el tener colmadas las manos»; o sea, de alguna manera la destinación a una función sacerdotal (vv. 26-29), aunque en principio no es claro de parte de quién. El mismo Aarón, por su parte, con su hermana María, unos capítulos antes en Nm, han contestado la autoridad de Moisés (11,35-12,1). Una cierta ambigüedad, por lo menos hasta un cierto momento, empaña su figura. A propósito de esto se pueden leer con provecho las páginas sobre Aarón y la evolución de su figura en las diversas tradiciones conservadas, y a veces modificadas, en los diferentes libros del Antiguo Testamento, en R. DE VAUX, Les institutions de l'Ancien Testament II. Paris, 1960, pp. 263ss. Retengo esta frase: «Dans les plus anciennes traditions du Pentateuque, Aaron est une figure assez floue qui s'est peu à peu precisée... Dans la tradition sacerdotale du Pentateuque, la figure d'Aaron est toute différente...» (ibid.). En los textos que ahora examinamos ambas afirmaciones se comprueban. 
ramas secas de algún árbol son productos artificiales de madera tallada. Si es así, se explica mejor que se puedan escribir sobre ellos los nombres de los «príncipes» de las tribus, mientras resalta más el prodigio del florecimiento de uno de ellos. El cetro lleva el nombre de Aarón en el que corresponde a la tribu de Leví (v. 18). Moisés, que había escrito primero él mismo los nombres de cada tribu, los deposita en el Tabernáculo frente al arca; es decir, en presencia del Señor. La vara o el cetro que al día siguiente haya florecido señalará con este signo quién es el depositario de la autoridad de parte de Dios. Al día siguiente, la vara o el cetro que florece es la que lleva el nombre de Aarón, de la tribu de Leví, y con la flor ${ }^{20}$ habría producido el fruto: almendro ${ }^{21}$. Luego YHWH ordena a Moisés dejar el cetro de Aarón florecido depositado ante al arca en «custodia» y signo para que se acaben las murmuraciones y las rebeldías y no sean castigados con la muerte los culpables. El comentario de los israelitas no manifiesta sin embargo ninguna seguridad: el que se acerque al Tabernáculo morirá y «¿acaso moriremos todos?» (v. 28). Por lo menos, la dura lección parece haber sido aprendida.

El triste fin de Coré (y sus secuaces, si los tenía) ayuda a entender lo que sigue en el cap. 18. Estricta separación entre sacerdotes, levitas y profanos (zar); es decir, prácticamente el resto del pueblo de Israel. El texto está dirigido (por YHWH) a Aarón (y no tanto a Moisés), a sus hijos y «a la casa de tu padre», que se especifica enseguida como la «tribu de Leví» (v. 2): una comunidad aparte. En el seno de la cual hay también estrictas distinciones que no es lícito transgredir. Los sacerdotes, o sea, Aarón y sus hijos, llevan la responsabilidad del santuario (miqdash), de los objetos sacros, del Tabernáculo y del altar (sin duda, el del incienso); y luego se añade (v. 7): «Lo que está más allá del velo». Y son responsables de que estos límites no sean transgredidos por nadie bajo pena de muerte para los transgresores y para ellos mismos. Los restantes miembros de la tribu, o sea, los levitas, están para servir a los sacerdotes, sin

${ }^{20}$ La palabra usada aquí es la misma que designa el ornamento de oro puesto en la frente del sumo sacerdote: sis (cf. Ex 39,30, etc.).

${ }^{21}$ Como es sabido, el mismo hecho de la vara florecida ha sido utilizado en muchas representaciones de la selección del candidato al matrimonio con María Virgen en la persona de José, solo que aquí los candidatos fracasados rompen sus varas; así, por ejemplo, en el precioso mosaico de San Salvador in Chora, en Constantinopla (hoy Estambul). Esta figuración viene de algún escrito apócrifo. Los que consulto (Protoevangelio de Santiago 9; Evangelio del Pseudo-Mateo 8,3), sin embargo, presentan a José designado por una paloma que parte en vuelo de su vara sin decir nada de varas florecidas o rotas. 
violar los límites impuestos ${ }^{22}$. Si hiciera todavía falta, aquí la distinción entre las dos categorías es plenamente ratificada. Y se demuestra una vez más que a la característica del libro de Números y a su identidad distintiva pertenece la definitiva determinación de esta distinción, que de aquí en adelante se incorpora a la concepción de la misma comunidad de Israel aun después de la ruina del Templo ${ }^{23}$. Corresponde en esta perspectiva interrogarse, según este capítulo, qué le toca al pueblo o a la comunidad y la respuesta se encuentra aquí mismo, al menos desde este punto de vista tan radicalmente $\ll$ clerical» ${ }^{24}$.

\section{La porción de levitas y sacerdotes en los sacrificios y otras ofrendas del pueblo de Israel: es decir, la fuentedel respectivo sustento}

Lo que ahora sigue, siempre en un mensaje dirigido a Aarón (y a nadie más, ni siquiera a sus hijos, que se supone están incluidos en el jefe de la familia), especifica con toda posible precisión lo que toca a Aarón (y a sus hijos) por una parte (8-20) y a los simples levitas («hijos de Leví» en el original) por otra (21-24; 25-32), lo cual tiene el doble efecto, sobre todo para los segundos, de asegurar su sustento y ratificar la insalvable distancia entre unos y otros. Aquí se dice ya, como se dirá después en Dt $(18,1 \mathrm{ss})$ de

${ }^{22}$ En los vv. 2 y 4 se usa el verbo lhw, «asociarse»; en el primer caso de la «tribu de Leví» como tal, en el segundo, de los «hijos de Aarón». El objeto de la asociación en el primer caso son precisamente estos; en el segundo (con el pronombre en singular), el mismo Aarón. No se puede dejar de notar que el verbo en cuestión gramaticalmente podría ser simplemente el denominativo de lewi.

${ }^{23}$ Semejante distinción de categorías dentro de la misma comunidad se explica mejor sin duda después de Ezequiel y de la vuelta del exilio, haciendo ahora abstracción de los problemas históricos y críticos que esto plantea.

${ }^{24}$ Que permanece en el Israel postbíblico. Cf. un ejemplo típico en la Misná, Gittin 5,8 (en la versión inglesa de H. DanBy. Oxford, University Press, 1933): «A priest reads first, and after him a levite, and after him an Israelite»; Hodayoth 3,8 (misma versión): «A priest precedes a levite, a levite an Israelite, an Israelite a bastard», pero se añade enseguida significativamente: «... but if a bastard is learned in the Law and a High Priest is ignorant of the Law, the bastard that is learned in the Law precedes the High Priest who of ignorant in the Law». El NT conoce también la distinción: Lc 10,32 (la parábola del buen samaritano, donde, sin embargo, el sacerdote pasa antes); Jn 1,19: «Los Judíos enviaron sacerdotes y levitas desde Jerusalén» (misma observación); Hch 4,36: Bernabé es un «levita» nacido en Chipre; Zacarías es un sacerdote en funciones (Lc 1,5), etc. 
todos los «sacerdotes levitas», que entre «los israelitas» no tendrán una porción propia de herencia (cf. Nm 18,21.23b) ${ }^{25}$. Por el momento, su fuente de sustento, bien distinta de la de los sacerdotes (sobre la cual volveremos enseguida, pero la diferencia se percibe mejor comenzando por los levitas), son los «diezmos de Israel». Los israelitas están obligados a pagar el diezmo de todos sus productos agrícolas: la ley presupuesta por Lv 27,30ss está expresamente promulgada (y en una forma bien diversa de lo que aquí se implica) en Dt $14,22-23^{26}$, y no en otro texto legal. En el presente texto es justificada en función del servicio (secundario, pero real) que los levitas prestan en el Tabernáculo, del cual los israelitas están del todo apartados, además de su carencia de herencia en Israel (hasta ahora). Pero ni siquiera el total de los diezmos queda a los levitas.

El pasaje siguiente: instrucción de YHWH a Moisés (y no a Aarón) (18,25-29), prescribe todavía que el diezmo del diezmo del trigo y del lagar sea una porción reservada (terumah) al Señor de todo lo que reciban de la comunidad, y esa porción «reservada» sea entregada a Aarón, el sacerdote. Y deberá ser la «mejor parte» (helbo) porque es «consagrada» (v. 29) al Señor. Una especie de apéndice (vv. 30-32), siempre en nombre del Señor a través de Moisés, autoriza a los levitas a comer su parte con los suyos en cualquier lugar, siendo esto su compensación (sakar) por su servicio. Y así no estarán tentados de comer los «dones sacros» de los hijos de Israel, profanándolos y siendo por eso castigados con la muerte ${ }^{27}$.

Veamos ahora, invirtiendo el orden del texto, la parte que toca a los sacerdotes, a Aarón y a sus hijos, que cargan con la responsabilidad del santuario (miqdash) y de su «sacerdocio». A ellos se les conceden como don los levitas, aunque son en realidad «concedidos» (netinim) a YHWH para el servicio de lo que requiere el Tabernáculo. Dicho esto, se especifica en una nueva comunicación a Aarón $\operatorname{solo}^{28}$ que lo que les toca es ante todo

${ }^{25}$ Esto no obstante, después, en este mismo libro, aparecerán las ciudades «levíticas», con sus correspondientes territorios (cf. 35,1-8), que examinaremos a su tiempo.

${ }^{26}$ Aquí se recomienda (cf. v. 27: «No olvides al levita que vive en tus ciudades») tener presente al levita, pero el diezmo es consumido por el propietario y su familia, y no entregado entero al levita. La ley que leemos en $\mathrm{Nm}$ es propia de este libro.

${ }^{27}$ La repetición aquí (v. 32) de la expresión la «mejor parte» (helbo) confunde un tanto: es la que ha sido entregada a Aarón. Puede ser la «mejor parte» de lo que queda. Sea como fuere, se ve el proceso de «clericalización» creciente de la sociedad israelita.

${ }^{28}$ Esto tampoco es casual: estas comunicaciones a Aarón son a la par una discreta indicación de su origen. No se las atribuye a la revelación de Moisés en el Sinaí. Vienen en realidad de la comunidad sacerdotal, predominante en Israel después del exilio. El documento $\mathrm{P}$, sin duda, en un aspecto especial del mismo. 
la terumah, o sea, lo que corresponde al Señor de todos los «dones sacros» y no es consumido por el fuego, sea de los sacrificios incruentos como de los que se ofrecen por el «pecado», como de los que se ofrecen en reparación ('asham). La referencia implícita es Lv 1-6. Y se añade que también las partes de los sacrificios «presentadas» con el gesto especial de presentación a YHWH (la tenufah) les corresponden. Y no solo a los miembros masculinos de la familia (es decir, propiamente los sacerdotes), sino también a la parte femenina de la misma (v. 11: «A ti, a tus hijos y a tus hijas», v. 19). La única condición es que estén ritualmente puros (tahor; cf. vv. 11b.13b). La enumeración sigue con lo mejor de los productos de la tierra: el aceite (heleb), el mosto y el trigo, y las primicias ofrecidas a YHWH. Y todavía con los «primeros frutos» (bikkurim), que también se le ofrecen. Lo que es de alguna manera «separado» (herem; es decir, hecho «anatema») para YHWH, asimismo pertenece a Aarón y sus hijos. Y los primogénitos de hombres y animales son igualmente destinados antes al sacerdocio, necesariamente rescatados el primer mes los primeros, como los «impuros» de los otros con la indicación del precio del rescate: cinco siclos del valor del santuario.

Las determinaciones se completan ahora con la especial norma para la disposición de los primogénitos de los animales domésticos: bovinos, ovinos, caprinos; no se los redime propiamente, se los sacrifica, la sangre se derrama sobre el altar, la grasa se consume y la carne queda para los sacerdotes, previo el rito de presentación del pecho y de la pata derecha. Se concluye con una síntesis que abarca todo lo anterior: lo adjudica nuevamente a los hijos e hijas de Aarón, o sea, a la comunidad sacerdotal como tal, y se ratifica todo esto como un precepto (hoq) perpetuo dos veces (vv. 11b.19b; en este último texto, este precepto es descrito como un «pacto de sal» entre YHWH y el sacerdocio aarónida, a semejanza de los pactos entre personas y entre naciones) ${ }^{29}$. Una última palabra del Señor a Aarón (v. 20) de alguna manera sirve de justificación de todo lo anteriormente concedido con la misma fórmula que ya conocemos para los levitas: «No tendrás ni herencia ni parte en Israel: yo soy tu parte y tu herencia [hay que notar el quiasmo, que acentúa

${ }^{29}$ Donde el uso de la sal brinda el sentido de la incorruptibilidad y de la perpetuidad del pacto. En otros términos, cuanto está dispuesto aquí no se cambia ni se vuelve ya atrás. Para seguridad de los interesados. Además de aquí, la expresión «pacto de sal» aparece una sola vez en el TM: $2 \mathrm{Cr}$ 13,5, en boca del rey Abías a propósito del pacto con David (Libro del Pueblo de Dios: «pacto indestructible»). Invertida, si se quiere, la expresión se lee en Lv 2,13, cuando se prescribe para la ofrenda vegetal: «Nunca dejarás que falte a tu oblación la sal de la alianza con tu Dios». Como tal, se comprueba que es una expresión de uso tardío, aunque el uso de la sal en la celebración de un pacto es seguramente antiguo. Mal 2,4 menciona también un pacto con Leví. 
la expresión] entre los israelitas». Una vez más, Israel aparece como una sociedad decididamente inclinada hacia un sacerdocio privilegiado aun desde el punto de vista de su sustento cotidiano, respecto sin duda de los simples levitas, como ya se desprendía de la norma anterior: a estos ni siquiera les tocan los diezmos completos, sino además respecto de los otros miembros de la comunidad, buena parte de cuya producción vegetal y animal es destinada al culto y, por esa misma vía, al sustento de la casta sacerdotal.

A esta altura de las cosas hemos llegado a la mitad del libro de los Números, tal como está actualmente dividido, de manera por cierto artificial: 18 capítulos sobre 36 . Y hemos comprobado que esta primera mitad, se puede justamente decir, está caracterizada o distinguida por la cuestión de la presencia de los levitas, su identidad propia y la consiguiente relación positiva y negativa que tienen con la casta sacerdotal por excelencia: los aarónidas. Y, como hemos notado más de una vez, de esta disposición estructural no se vuelve ya atrás.

En esta segunda parte, levitas y sacerdotes están ciertamente menos presentes, pero no del todo ausentes; como se verá en lo que ahora sigue y que intentamos exponer con cierto detalle, bien conscientes de la dificultad de los textos.

\section{El segundo censo de las once tribus y el especial de los levitas}

A continuación del desastre de Peor (cap. 25) y en vista ya del ingreso en la Tierra prometida y de su división entre las tribus, nos encontramos con un largo pasaje paralelo al que leíamos al principio del libro: un segundo censo de todos los miembros de las once tribus, artificialmente mantenido, sin embargo, el número de doce gracias a la dicotomía de la tribu de José en sus dos componentes: Manasés y Efraín (26,1-51), y se registra a los miembros varones mayores de veinte años «aptos para la guerra en Israel» (v. 1), porque de eso se trata; de la conquista del territorio. El resultado es ligeramente inferior al del primer censo: $601.730^{30}$. Los levitas, como

${ }^{30}$ Un inciso al final de los censos $(26,63-65)$ responde a la dificultad que se desprende de la lectura de las varias hecatombes a que los israelitas han sido sometidos por su culpa a lo largo del recorrido por el desierto, siempre cuidadosamente indicadas por la cifra del número de muertos lla última hasta ahora en Peor: 24.000, cf. 25,9). Se nos dice entonces: «En el censo de los israelitas en las estepas de Moab... no figuró ninguno de los que Moisés y el sacerdote Aarón habían registrado en el desierto del Sinaí [es decir, el censo del cap. 1]. Porque el Señor había 
en el censo del principio del libro, son registrados aparte (vv.57-62), sin ninguna indicación especial, sino la que ya conocemos: los mayores de un mes, y figuran aparte porque «no se les había asignado una propiedad hereditaria» en Israel (v. 62). De suyo entonces no toman parte en la conquista. Pero el resultado es aquí también distinto: si las tres ramas principales son las mismas y en el mismo orden del cap. 3: guersonitas, quehatitas y meraritas, la lista de clanes que sigue es distinta y vuelve al epónimo de la tribu, Leví, para desviarse enseguida al origen de Moisés y Aarón, siempre, sin embargo, quehatitas, prescindiendo del resto de los clanes. La suma numérica, a diferencia de la de los demás israelitas, es ligeramente superior al número del censo anterior: 23.000 (contra 22.000 de 3,29). Y se insiste en que los levitas son excluidos del censo común de las demás tribus «porque no se les había asignado una propiedad hereditaria entre los demás israelitas» (v. 62). Como se verá enseguida, esta indicación ha sido después enteramente superada.

\section{Normas para la repartición del botín de guerra: parte especial de los levitas}

En el ataque contra Madián (cap. 31), bastante artificialmente introducido en el relato de la última etapa antes de la conquista, en las estepas de Moab, y puesto en relación con la próxima muerte de Moisés, anunciada desde ya (cf. 27,12-22), aunque recién la leeremos en el cap. 34 de Dt, importan sobre todo las normas para la distribución del botín, objeto de una comunicación divina (31,25-54). Semejante acto, más bien de suyo ajeno a toda regla en la cruda realidad de la guerra, adquiere aquí un carácter religioso: el principal responsable es inesperadamente el sacerdote Eleazar, hijo y sucesor de Aarón, fallecido en el monte Hor (20,22-29). De hecho, una cierta parte del botín, incluso en animales y personas, es «un tributo para el Señor» (v. 28): una vida de cada quinientos. Los oficiales, además libremente, en vista de que no han perdido ni un solo soldado, ofrecen al Señor todo el oro y las joyas que han recogido en el saqueo (vv. 48ss), que Moisés y Eleazar reciben y llevan al Tabernáculo «como memorial de los israelitas delante del Señor» (v. 54). Se trata, por consiguiente, de una especie de rito, más bien ajeno al resultado de una batalla y al consiguiente

dicho de ellos: "Morirán en el desierto". Ninguno de ellos sobrevivió, excepto Caleb, hijo de Jefuné, y Josué, hijo de Nun». Parece claro que la diferencia arriba notada entre los resultados de ambos censos no basta para justificar esta afirmación, que una vez más no pretende tener valor de exacta estadística. 
saqueo. En esta especie de rito, también los levitas tienen su parte. Las instrucciones divinas que Moisés recibe los incluyen del siguiente modo (v. 30): de la mitad del botín que corresponde a los no combatientes, o sea, a los demás israelitas, «tanto de las personas como de los animales... tomarás una vida por cada cincuenta y se las entregarás a los levitas que realizan tareas en la Morada del Señor» (ibid.). Los sacerdotes, se deduce de lo dicho ya, se harán cargo de los objetos preciosos.

\section{Las ciudades de los levitas}

Esta disposición, aun considerada puramente ideal, no deja de implicar como consecuencia, en su contexto, que los levitas podían y debían tener, a pesar del principio tantas veces repetido de su carencia de toda propiedad (cf., por ejemplo, supra 26,62), algún territorio propio. Es precisamente lo que se legisla en el cap. 35 sobre las ciudades de los levitas. La disposición (como todas o casi todas) viene del mismo YHWH por medio de Moisés; es decir, tiene carácter sacro. Los israelitas, una vez instalados en su tierra y fundadas sus ciudades (u ocupadas las ya existentes y hechas propias), son obligados a destinar cuarenta y ocho de ellas a los levitas. O sea, las seis destinadas al refugio de los responsables de muertes involuntarias (bishgagah, cf. v. 11) más otras cuarenta y dos. Y esto con los territorios circundantes calculados de manera explícita y completa: mil codos a partir del muro de las respectivas ciudades (v. 4b.), que enseguida resultan dos mil hacia los cuatro puntos cardinales (v. 5). En nuestra medida (por lo menos según el Libro del Pueblo de Dios): dos mil metros en las cuatro direcciones. Naturalmente, si se trata de una superficie cuadrada, sería menor que si la superficie es considerada una circunferencia. Sea como fuere, los levitas disponen entonces, o dispondrán, como se dice expresamente (v. 3), de animales domésticos. Y nada impide, al contrario, que dediquen sus campos también a la siembra. Como última indicación (v. 8) se dice que los israelitas que hubieran recibido una porción mayor del país conquistado destinen a los levitas un mayor número de ciudades $^{31}$ y los que hubieran recibido una porción menor, menor ${ }^{32}$.

${ }^{31}$ Que se tratara de una «exigencia» de los levitas, como dice la versión del v. 8 de El libro del Pueblo de Dios, es una añadidura propia.

${ }^{32}$ El libro de Josué (cap. 21) registra fielmente la realización de esta disposición con la lista de las ciudades que cada una de las tres ramas o clanes de Leví recibieron de las distintas tribus. Las ciudades, según este relato, se distribuyeron 


\section{Algunas consideraciones generales}

Según un primer recuento, el término «levitas» aparece unas cincuenta veces en el libro de Números, frecuencia solamente superada en el AT por la frecuencia en los dos libros de las Crónicas (que, por cierto, no son en realidad más que uno artificialmente dividido), donde se lo cuenta unas cien veces ${ }^{33}$. Esto es ya en sí significativo.

Pero sobre todo es en Nm donde los levitas encuentran su lugar en la institución cultual de Israel, como distintos de los sacerdotes hijos de Aarón, su misión propia respecto del Santuario, sus derechos en la comunidad de Israel y hasta el monto de su participación en la división de un eventual saqueo después de la derrota de un enemigo. El conflicto en el cual se ven envueltos por culpa de uno de ellos ayuda a definir mejor su posición frente a los miembros de la casta sacerdotal: Aarón y sus hijos.

Además, encuentran o reciben en el mismo libro lo que se puede llamar su estatuto «civil»: es decir, a pesar de la constante distinción respecto de las restantes tribus, porque no tienen «una propiedad hereditaria» en Israel (cf. 27,62), reciben al fin cuarenta y ocho ciudades con los respectivos territorios en los de las demás tribus ${ }^{34}$.

«por sorteo» (v. 4 etc.). Pero lo notable es que, en esta distribución, se incluyen entre los quehatitas «los descendientes de Aarón, el sacerdote» (v. 4). Y se especifica luego (v. 19): «Trece ciudades y sus campos de pastoreo era el total de las ciudades pertenecientes a los sacerdotes hijos de Aarón», mientras a «los otros levitas descendientes de Quehat» les tocan «en total diez ciudades con sus campos de pastoreo» (v. 26). Trece también a los guersonitas (v. 33) y doce a los meraritas (v. 40). Se pregunta uno si tal era la intención original de la disposición del cap. 35 de Números, donde entonces el término «levita» no tendría el sentido restringido que tiene prácticamente a lo largo de todo el libro. Y así los sacerdotes, además de la parte del león ya asignada a ellos en el ejercicio de su función cultual según el cap. 18, dispondrían de propiedades raíces, lo cual aumentaría todavía más la desigualdad con los simples levitas.

${ }^{33}$ Desde este punto de vista es ilustrativo comprobar la tan desigual presencia del término (sobre todo en su forma plural) en los diferentes libros del AT. Las referencias más antiguas (o sea, en textos indiscutiblemente antiguos) son todas en singular, como en los conocidos textos de Jue 17-20, y se refieren a algún levita por así decir autónomo.

${ }^{34}$ Es difícil pensar que esto sea fictitious, como afirma G. B. GRAY en su comentario (Numbers. ICC. Edinburgh, T. \& T. Clark, 1956, third impression, p. 465) y que Levitical cities in the meaning of the Law never existed (ibid.). Las había «sacerdotales», como hemos visto. ¿Por qué, al menos en principio, no también levíticas? Cf., por lo demás, 1 Cr 6,39-61. 
En síntesis, la identidad de la categoría de estos miembros de la comunidad de Israel se lee en la redacción «sacerdotal» de este libro del Pentateuco. Y no, como hemos repetido ya, en el libro que lleva precisamente el nombre de Levítico (al menos desde los LXX en adelante). Anomalía que espera todavía una explicación adecuada, pero que pertenece más bien el estudio de la traducción y redacción final de la versión recién citada.

Sea como fuere, el hecho es que en los libros más recientes del texto hebreo del Antiguo Testamento, es a saber, por ejemplo, los dos libros de las Crónicas, los levitas ocupan un lugar y ejercen una función o funciones completamente ausentes en los libros anteriores. Una simple comprobación de lo cual puede consistir en la comparación de algunos textos parale$\operatorname{los}^{35}$ de los libros de los Reyes y los correspondientes de las Crónicas, para limitarse más que a estos, porque estos últimos contienen varios textos sobre los levitas y sus actividades completamente ignorados por los primeros, como cualquier sinopsis de ambos libros hace fácilmente patente.

Esto significa por lo menos que esta categoría específica de personas «sacras» adquirió a partir de un cierto momento una importancia y un estatuto propios ${ }^{36}$, de los cuales hasta ese momento carecían. De esto,

35 Un interesante ejemplo (entre otros muchos) se puede ver en el episodio de la «revolución» de Yehoyadá contra Atalía y el papel que allí se asigna a los levitas en la versión de $2 \mathrm{Cr} 23,1$ ss.

${ }^{36}$ Estatuto sin duda completado, con atención específica en los libros de las Crónicas, donde es atribuido a David y Salomón. En 1 Cr 6,16-17, David constituye los levitas «cantores» en su santuario «provisorio», pero en la perspectiva real del libro, ya en el Templo (todavía futuro). También son los «porteros» $(9,17 \mathrm{ss})$ con referencia retroactiva a la función en el tiempo del desierto, destinada a justificar la función presente: «Se ocupan del culto [siempre los levitas] como guardianes de los umbrales de la Carpa, porque sus padres [de los actuales] habían tenido a su cargo la guardia del acceso al campamento del Señor» (v. 19), y la conexión con la actualidad (en realidad todavía futura a esta altura de $\mathrm{Cr}$ ): «Tanto ellos como sus hijos tenían bajo su custodia la entrada de la Carpa; es decir, de la casa del Señor» (v. 22); «... tenían a su cargo las cámaras y los tesoros de la Casa de Dios» (v. 26), también «el cuidado de los utensilios de culto... todos los vasos sagrados, la harina de las ofrendas, el vino, el aceite, el incienso y los aromas» (vv. 28-29). Y «entre los quehatitas, algunos estaban encargados de preparar cada sábado los panes de la ofrenda» (v. 30). Son los levitas los que «transportan el Arca del Señor» y no solamente los sacerdotes, «sosteniéndola sobre sus hombros con unas andas» $(15,14 s s)$, disposición atribuida a Moisés «según la palabra de Dios» (ibid.), mientras otros levitas cantan y ejecutan instrumentos (vv. 16-21); en realidad, su ocupación que se puede definir principal, atribuida además a miembros de los tres clanes (cf. 6,14-32), proyectada a su vez en el tiempo normativo del desierto: «Ellos servían como cantores ante la Morada...» (cf. v. 17). Y ha dejado su huella en el Salterio; cf., por ejemplo, los salmos de Asaf (50; 73-83), Hemán (88), etc. Los sacerdo- 
el libro de los Números en su actual redacción en el Pentateuco presentaría el momento decisivo. Lo cual nos mueve a juzgar que este hecho tan especial pertenece, en una cierta pero verdadera medida, a su propia identidad.

\section{Una posible hipótesis explicativa}

Queda por explicar, en la medida al menos de lo posible, ¿por qué el último redactor (o redactores) de P resolvió dedicar este parte importante de su escrito (o escritos) a la presentación de semejante identidad? Aquí se hace necesario aguzar el ingenio, si bien es posible proponer alguna hipótesis.

Por una parte, se puede pensar en un cierto descrédito del sacerdocio como tal, a causa, por ejemplo, de su tolerancia ante el sincretismo del pueblo, sobre todo en los santuarios locales, sin excluir el santuario central (cf. Ez 44,5-14; 2 Re 23,9) ${ }^{37}$. Distinguidas de hecho dos categorías de miembros del clero, como parece desprenderse de estos textos, se hacía preciso determinar con precisión las competencias de cada una, también y quizá ante todo por lo que toca a los medios de subsistencia respectivos. Que esto no se hizo sin tensiones y dificultades los mismos textos de Nm lo revelan.

De cualquier modo, se hacía necesario llegar a un cierto estatuto dotado de autoridad indiscutible. Para esto, el único recurso era fundarse en la autoridad de Moisés y en su mandato divino, volviendo por consiguiente a la época considerada ideal de la existencia y formación del pueblo y sus instituciones, es decir, a la revelación del Sinaí. Y aun aquí se pueden reconocer varios pasos y no una evolución rectilínea. Uno de estos pasos es, sin duda, la atribución a David de otras funciones exclusivas de los levitas

tes, en cambio, «tocan las trompetas» (v. 24), como son ellos los que hacen «la mezcla de los perfumes aromáticos» $(9,30)$. Salomón hace un nuevo censo de los levitas $(23,3 \mathrm{ss})$ y determina sus actividades «conforme a estas últimas disposiciones de David» (vv. 27ss, que repite prácticamente el texto ya citado del cap. 9), pero los levitas funcionan también como «escribas y jueces» (v. 3), etc. La creciente importancia de los levitas en el Templo salomónico, como antes en el santuario de David, es así manifiesta, a la par de su neta diferencia de los sacerdotes «descendientes de Aarón» con sus clases $(24,1$ ss).

${ }^{37}$ En los libros de las Crónicas, los sacerdotes, cuando aparecen en la historia del reino de Judá, se comportan casi siempre ejemplarmente. Pero se puede decir que el proscenio está más bien ocupado por los levitas. 
registradas en los libros de las Crónicas, ratificadas y aun acentuadas por Salomón, como herencia de su padre. De aquí, sin embargo, no se vuelve ya atrás, y los levitas constituyen, según se ha dicho ya más arriba, una componente esencial de la sociedad israelita al tiempo del Nuevo Testamento, y por cierto también después ${ }^{38}$.

Cardenal Jorge Mejía Ciudad del Vaticano

${ }^{38}$ Acerca del tema se puede leer con provecho, pero también con discernimiento, el artículo «Levites and Priests», de Merlin D. ReHM, en el vol. 4 (1992), pp. 297310, de The Anchor Bible Dictionary, con bibliografía hasta esa fecha, además, por supuesto, de los comentarios a los libros bíblicos citados en el texto, comenzando por los comentarios a $\mathrm{Nm}$ (que no abundan). 